\title{
Teaching Reflection of My Life and Death Education
}

\author{
Quanlei zhang \\ Institute of Education, Langfang Teacher's College, Langfang, 065000, China
}

Keywords: life and death education, death fear, funeral parlour

\begin{abstract}
The life growth and life experience often influence the teaching and research of teachers, the special death experience brought by the psychological fear brought by the horror of self-death and staring at the death of others makes the author fall in love with the teaching of life and death education. The author carries out the theoretical teaching of life and death education among the university students in the form of general education, and also carries out practical teaching in the form of visiting the fire fighting education base, life poem recitation and compiling epitaph and testament, watching life and death films, simulating air crash game, visiting funeral parlour and tomb, brining active life influence to the students, helping them think over life and face death calmly, obtaining good teaching achievement and harvesting the experience and lesson to carry out practical teaching.
\end{abstract}

\section{Reasons to carry out teaching of life and death education}

Education comes from life and ideology is rooted in experience. The personal life growth course and life experience often influence teachers' teaching and research. Staring at the death during illness and the experience of closely contacting others' death makes me have deep experience to death, and an intuitive and vivid fear experience, which promotes the author think over death more deeply.

1. Staring at the sun: fear of self-death

"You cannot stare at death if you cannot star at the sun". In his book Staring at the Sun, Overcoming the Terror of Death, Owen Aronne pointed out that death is like the dazzling sun and one cannot stare at it. People often "become panic at the mention of death", as if death always brings insurmountable anxiety and death terror to people. However, for the growing children and young people, death seems to be far away. But to some of them, the threat and terror of death sweep suddenly sometimes. It was in the period of salt of youth that I encountered death so early.

Illness often makes people think of death. My first breakout of terror of death was caused by illness. At the very beginning when I went to study in a metropolis, due to lack of common sense of life-not know how to live and maintain health and unable to adapt to the environment, for example, allergic to tail gas, I suffered from disease of respiratory system and then kidney stone. The repeated illness forced me go in and out of the outpatient departments and wards of various hospitals. My severe and repeated cough, continuous chest distress, continuous torment of waist pain, the long treatment process, heart loneliness and isolation in a foreign place at the very beginning, no place to tell negative moods, the panic face and nausea reaction of patients with serious kidney disease in the same ward, physiological pain, psychological suffering, worry of patient's family members, and various sadness..., all swept to me suddenly in a short time, and my heart was firmly occupied by the terror of death.

I began to have a terror death from illness, in anxiety and terror, I was suspected to have a lot of diseases continuously, so my life was in a mess, and I fell into the vicious circle of illness-terrorsuspected illness-illness. In those days, I was under the shadow of death and was in a constant state of anxiety, with disordered diet and sleep. The continuous illness and ignorance to illness made me misunderstand that I had an incurable disease and once I even had the idea of seeking for death. Having in mind the tragic scene that "my parents pinch and scrape and work hard to cultivate me and afford my study for more than 20 years, my family is heavily in debt and my parents have to lose the family fortune and request relatives to treat my diseases", I gradually had the idea of "it is better to die than living". Shortly after I was discharged, in the prosperous metropolis, and in a foreign place where I felt lonely, I wandered in front of the window on the $6^{\text {th }}$ floor for countless cold nights, and experienced the inner struggle of pain... Fortunately, I did not make that decision 
finally. With time passing by, my illness was gradually improved, and I also gradually got out of the shadow of death.

That not defeating you will make you stronger (Nietzsche). The suffering of illness made me more frank and calmed to death and have deeper thinking over the problem of life and death.

2. Intimate contacting: moving by others' death

It was after work that I experienced death for the second time. One of my retired colleagues died of leukemia. As a staff sent by my unit, I participated in the funeral and cremation of the death in the whole course. I contact the dead body for the first time in the body makeup room. When assisting the family members of the death to carry the swelling dead body, staring at the panic face of the dead, I had my terror to the peak. Death presented in front of the living so vividly, several months ago, we often met each other, but today he has passed, life is so fragile... This experience of staring at and closely contact dead body brought me with the deep terror to death and also stimulated by deep thinking over life and death.

Brushing past death (staring at the terror of self-death) and the first close contacting with death (contact dead body, and witnessing others' death) made me have a deeper and more intuitive feeling to death and had a unique feeling and understanding to death. From then on, I was indissoluble bound to death, and I began to concern various death phenomena in terror and trembling, thought over the issue of death and what was death on earth, why it was so terrible and whether there is a post-death world. I also gradually red death, Lu Youqing, Ziyou, Yuan Xiaojuan, Fu Weixun, Yu Juan..., their unfortunate suffering made me regret, while their life message and death notes left when staring at death also triggered my thinking continuously: how to take the road of life? What kind of lifestyle should be established? How to spend every living day? What is the most important on earth in life?...

As early as in 2006, I added the special topic of life and death in my main course New Concept of International Education, and later I gradually carried out the theoretical and practical teachings of life and death.

\section{Opening condition and content introduction of life and death education course}

1. Change of course name: the name of my life and death education course has changed: New Concept of International Education-New Concept of Contemporary-Life Education of University Students, with the change of course name, the teaching contents have also experienced transformation from partial opening of life and death education, dominated by life and death education contents and full opening of life and death education.

2. Course description: this course is a selective course of general education, aimed at the normal and non-normal students of the whole university, with one class opened each semester, totally 150 persons and 2 class hours every week, totally 32 class hours. The course contents consist of life education and death education, first, the life education theory and practical teaching, including life awareness education, survival skill education, life significance, life value education and other theoretical teachings, as well as visiting to fire fighting education base, life motivation concert, poem recitation, sketch demonstration and the corresponding participating and experiential practical teaching; second, death education theoretical and practical teaching, the death education theory includes death and death education overview, death education overview around the world, death concept of different religions, death philosophy, euthanasia and suicide etc. and the death education practice includes compiling of epitaph, testament, watching life and death films, simulating air crash game, visiting funeral parlour, simulating memorial meeting and visiting tomb etc.

\section{Practical activity and reflection of visiting funeral parlour}

Death education is one of the important implementation approaches of life education. While carrying out the life and death theoretical education, I have also carried out and strengthened the practical teaching of life and death education. Visiting funeral parlour is one of the practical teaching forms of life and death education. My leading students to visit funeral parlour is influenced by the visiting activity of Jingshan Middle School in Haikou, but the fundamental cause for me to carry out death education is my close contact with death twice, the deep feeling and understanding 
to death also make ne have a deep empathy to those threatened by death, I help myself for the purpose of helping others and all these make me have a strong determination to carry out life and death practical education.

1. Overview of visiting to funeral parlour

Since I opened the life education course among university students in 2007, I have successively organized the activity to visit funeral parlour and simulate the memorial meeting for three times (the first time, December 7, 2007; the second time, December 13, 2008 and the third time, April 23, 2011), with good effect. The visiting was divided into three parts: first, the staff of funeral parlour explained the origin of cremation and relevant customs, second, visiting the cremation furnace, bone ash screening table, dead body makeup room, mortuary etc. under the operation guidance of the staff, and finally, carrying out simulative memorial meeting in the memorial hall with funeral music.

\section{Summary of visiting to funeral parlour}

First, the visiting is based on the principle of voluntariness

The visiting to funeral parlour and tomb etc. should be based on the principle of voluntary participation, because every person has different childhood experience, life experience, world concepts, value concepts, life and death concepts and religious beliefs. For these visiting activities, we should not impose uniformity in all cases, but should take the principle of voluntariness. After the event, it proved that our voluntariness principle was correct and it was also the respect to students, because indeed many students were full of terror to the activity such as visiting funeral parlour, and some students trembled repeatedly at the mention of death and even upon seeing of white cloth due to shadow of the trauma in childhood, and they even could not attend when discussing death. For these students, we should not force them, but can only hope them gradually overcome the psychological problem in the future growth. If they are unwilling to visit, but are forced to, upon visiting, they cannot defeat them, another extreme terror will cause to them. Meanwhile, the voluntariness principle also a process of being responsible for the students, a process of self-management and making students think over and stare at death. The process of deciding whether to visit is a process of thinking over death, and also a process of self-overcoming and defeating and a process of gradual desensitization to death. Thinking in this way, when making the decision to visit, actually they have defeated the terror of death and dare stare at death.

Second, there should be knowledge and psychological preparation to stare at death before visiting

Within two or three weeks before final decision to visit, the teacher and students had a wide theoretical discussion and thinking, the students had abundant theoretical knowledge to death and preliminary thinking over death. After class, whether in dormitory, or restaurant, the concern to death triggered by the class and visiting to funeral parlour has become the daily topic of the students, and they began to express opinion to the visit, think over whether they should visit, and this is a process of learning to think and staring at death.

First, through the indirect experience acquisition such as teaching, reading and discussion, the students obtained rational thinking and understanding to death, so that they had full knowledge and psychological preparation before witnessing the death site. They had rich understanding and knowledge, but such understanding and feelings were still not deep. The students' understanding to death still need the direct experience and feeling. Therefore, the practices such as visiting funeral parlour and tomb seem to be significant, which can make everyone obtain deep experience.

Third, pay attention to the visiting sequence

Looking back the three-time visiting to funeral parlour, overall, good effect has been obtained in the visiting activity, but relatively, the first visiting and the third one were more successful, mainly because of the visiting sequence. Our first and third visits to the funeral parlour were opposite to the process after death. The students first visited the cremation furnace, cremation room, watched the staff to simulate the cremation process, then demonstrated the screening of bone ash, then visited morgue, dead body makeup room, anatomy room, and finally simulated the memorial meeting with funeral music in the memorial hall. In such a reverse-sequence process, the students first had an intuitive understanding and feeling to death in curiosity and terror, and experienced a psychological of experiencing and feeling death. Finally, in the simulation of memorial meeting in the memorial hall, when the funeral music rang, the students had had rich emotional experience and in the funeral 
music, their terror and sadness to death were also drained in tears, and their feelings of living better and cherishing life were also upgraded. However, there were also lessons, in the second visiting, we took the correct visiting sequence, first we simulated the memorial meeting with funeral music in the memorial hall, and then visited the dead body makeup room, cremation room and other places. In this way, at the beginning, when the funeral rang, the students did not have deep intuitive understanding and experience to death, while their emotions of sadness and terror also were not drained with the funeral music in the later visiting process. Therefore, it is unreasonable to visit funeral parlour in positive sequence, only reverse sequence is reasonable.

Fourth, experiential practical teaching is an effective teaching form of life and death education

The existing practices and our time to visit the funeral parlour show that visiting funeral parlour is an effective teaching form of life and death education, overall, we obtained a good effect in the visiting activity. According to the review to the students' feeling after visiting funeral parlour, except the temporary terror before visiting, most of the students had a positive understanding, all thought that it was not in vain to visit the funeral parlour, and thought that it was a vivid and deep life and death education course and an unforgettable life experience. From then on, they ad deep understanding and thinking to life, reached a level to the understanding to life and reached a new height. All felt that they had realized the cherishing and valuing to life, knew that life does not only belong to themselves, a person lives not only for himself, but also for his family, friends and for the benefit of others and society, so they should not impulse, commit suicide, kill others and damage life. From then on, the students had also thought over the limitation and transience of life, how to live significantly and how to live with value etc. Finally, they concluded that life is limited and also transit, so everyone should live better, cherish and love life, making the limited life richer and more colorful.

The visiting activity also educated al students. Those not visiting also had a heart shock, causing their thinking over death, and they would activity inquire those visiting for feeling and discuss with them on life and death. They also expressed their pity in the assignment "why not visit funeral parlour" and felt it was a big pity in university not to grasp the opportunity to visit funeral parlour, and expressed if there would be another opportunity, they would visit.

Fifth, about the role of teachers

The life and death theory and practice teaching stresses the emotional experience. In the process of teaching, there is less knowledge lecturing and theoretical teaching, but more exploration, discussion, appreciation and sharing. The so-called experiential education is the best education. In the participation and personal experience, the students obtained intuitive understanding, new experience and the growth of heart. The teacher's role is to create scene, establish an experiential scene and sharing platform, and stimulate the students' thinking, and they play the role of leader and assistant. Meanwhile, teacher is also the joint participant, jointly sharing and growing with students in the experiential activity. Also, teacher is the activity reflector, continuously summarizing experience and lesson in the activity, so as to improve the teaching and do better in the future.

\section{Acknowledgments}

This paper is the staged achievement of college-level scientific research project of Langfang Teacher's College: "Class Teaching Reform of Higher Institutions under the Horizon of Life Education”, project number: LSJY200902

\section{References}

(1) Translated by Zhang Ya, written by Owen Aronne Staring at the Sun, Overcoming the Terror of Death, China Light Industry Press, 2009 edition

(2) Duan Dezhi, Western Death Philosophy, Peking University Press, 2006 edition

(3) Xinhua News Agency, Dispute on Middle School Students' Visit to Crematory in Haikou, Dazhong Net, July 29, 2006 